\title{
Challenges Facing the Sustainability of Adult and Continuing Education Programmes in Kenya
}

\author{
Iddah Kituyi Wanyama \\ School of Education, Mount Kenya University \\ iddah.kituyi@gmail.com
}

\section{Doi:10.5901/mjss.2014.v5n5p}

\begin{abstract}
Generally, not much research has been done in the area of Adult and Continuing Education Programmes (ACE) programmes in Kenya just as in other parts of the world. According to (Carron, 1990) Adult literacy has been a neglected area in terms of data collection and research, so much that finding even precise information about simple facts like the number of enrolled adults or instructors has been difficult in most cases. The few studies done however, indicate a lack of genuine commitment and seriousness in the recognition and actual implementation of the programmes to the extent they are not achieving the goal of adult literacy. This spaper therefore seeks to discuss the challenges facing the sustainability of the ACE programmes in Kenya.
\end{abstract}

Keywords: Education, Continuing Education, Adult, Learning, School

\section{Background}

Adult and Continuing Education Programmes (ACE) play a very crucial role in the development aspect of any society. They are widely recognized as a powerful tool for eradicating adult illiteracy, reducing poverty and attaining the Millennium Development Goals (MDGs). They provide basic Education and training opportunities to adults and out of school youth, aged fifteen years and above, who have either missed out on formal education in their childhood or for one reason or another, dropped out of school before attaining sustainable levels.

Despite their significance in Kenya's National development, ACE programmes have continued to face regression, stagnation or even erosion in most areas since the mid 1980s. According to recent research findings, ACE programmes still lag much behind what is needed, in respect to employability and an active citizenship, not just in Kenya but in most countries. (Hinzen, 2007) for instance points out that Adult Education provision in most countries is neither sufficient in quantity nor in quality and that related statistics are also limited in scope and often outdated.

The ACE Programmes in Kenya date back to the coming of Arab traders, European missionaries and explorers as well as the colonial officials in the late nineteenth Century who taught the adult converts industrial skills such as carpentry and masonry in addition to literacy, numeracy and agricultural skills, so as to have a skilled labor force. ((Ministry of Gender, Labor and Social Development, (2008). The program reached its near climax in 1979 with the launch of the National mass literacy program, before beginning a downward trend that almost saw its collapse until the recent interventions.

One of the key challenges has been the lack of coherent strategies, regulations and a policy to guide its operations. The Department of Adult Education (DAE) had for instance been placed in the Ministry of Gender, Labor and Social development instead of the Ministry of Education (MOE) thus denying it a direct vote as a mainstream activity of the ministry as well as the professional support and leadership that has contributed to the relative success of both the primary and secondary schools education programmes. The Government of Kenya (GOK) however, now has a clear policy on Adult and Continuing Education since June 2010, (BAE Act Cap 223 laws of Kenya).

The policy now provides for among other things guidance, co-ordination and facilitation of strategic planning which consequently enables easier identification and mobilization of resources for ACE programmes. The Directorate of Adult and Continuing Education (DACE) has also been transferred from the Ministry of Gender, Sports, Culture and Social services to the Ministry of Education (MOE). The Directorate is headed by a Director, assisted by several Deputy Directors as well as the Provincial, District and Divisional ACE Advisory Committees and the class committees.

The ACE Programmes in Kenya incorporate the Literacy programs, both Basic and the Post literacy programmes that help create a reading culture and ensure retention, improvement and application of the basic knowledge, attitudes 
and skills. The Adult and Continuing Education (ACE) and Community Education and Extension Programmes (CEEP) form the other types and seek to improve the knowledge, vocational and Technical skills of both the literate and illiterate adults and youth.

The GOK, additionally, collaborates with various providers and stakeholders to mobilize resources and other efforts in the successful provision of ACE services such as NGOs, CSOs, FBOs and CBOs as well as participating in local and international charters and forums that recognize Education as a fundamental human right to improve ACE programmes such as the World Declaration on Education For All, (EFA) (Jomtien, Thailand, 1990).

\section{Theoretical framework- the Human Capital Theory and Education}

The theory was propounded by among others Adam Smith, the British Economist (1776), Schulz, (1971), Sakanota and Powers (1995) and Psacharopoulos and Wood hall (1997). The theory rests on the assumption that formal Education is highly instrumental and even necessary to improve the production capacity of a population. According to the Human capital Theorists, an educated population is a productive population.

According to Psacharopoulos and Woodhall (1997), Human resources constitute the ultimate basis of the wealth of a nation's capital and that natural resources are passive factors of production. Human beings are therefore the active agencies who accumulate capital, exploit natural resources, build social, economic and political organization and carry forward National development. The theory has been lent support by the economic success stories of such Asian countries like Hong Kong, Korea, Singapore and Taiwan that have achieved unprecedented rates of Economic growth through making large investments in Education. The theory has however been heavily critiqued for allowing the assumption that education is everything as far as Economic Growth is concerned. Fitzsimons, (1999) observes that society and culture cannot be arbitrarily split from the economy since both the society and culture shape the preference of individuals in various ways. Another criticism of the Theory arises from cases where Education has not provided the expected positive growth as in the case of Nigeria. In some cases, it has even increased inequalities in income distribution as well as increased tension and strain on the Educational experience which in turn impedes Economic, social and political development. The theory is however relevant to the study in that it calls for promotion of Education as a way of improving skills which in turn leads to technological advancements, entrepreneurship, increased income, well being of a community, promotion of democracy, reduction of poverty, ethnic tolerance, promotion of political participation, employment opportunities, good health as well as breaking the cycle of illiteracy just as ACE envisages.

\section{Challenges of ACE programmes in the world}

Most previous research done in the ACE area reveal that the governance of the programmes has not been developed globally hence, the divided policy discourse between the 'North' and the 'South' regarding the provision of ACE programmes. Many Country reports since 1997, for instance, reveal that very few countries have specific legislation that sets out the aims and regulating principles of ACE programmes, while others have not even prioritized ACE programmes in their educational and social policies (UNESCO, 2003). The 2002 conference on Adult Education in Sofia (Spain), for instance ascribed ACE challenges to lack of policy frameworks and structures required to advance the requirement of the programmes, (Rue de la Concorde 60, 2006).

The absence of the targets of ACE programmes among the Millennium Development Goals (MDGs) 2000, were also widely perceived to have signaled their low policy importance at the global level (Ouane, 2009). The convening of the international conferences on Adult Education (CONFINTEA 1- VI) since 1949 and especially the CONFINTEA VI conference held in December, 2009 in Belem, Brazil have however, re-affirmed and underscored the right of adults to basic education and skills, therefore resulting in the re-awakening and rejuvenated vigor in matters of Adult Education. Many countries have thus undertaken policy reviews among other things, as a measure to enhance the role of Adult Education in their countries' development.

Awareness of the key role of Adult Education has therefore increased in the majority of European countries. Out of the 27 plus European Union Member states, 17 countries have adopted ACE strategies and virtually all countries in the region have a policy on ACE especially in countries like Denmark, Iceland, Norway, Sweden and the United Kingdom. (Ouane, 2009). The participation rate for Adults in the program is reported to have been at $9.7 \%$ in 2007 , having increased from a paltry 7.15\% in 2000. In Ireland, the government developed the White Paper on Adult Education in 2000 and also established a forum of Adult Education Practitioners through the National Adult Learning Council (NALC).

In Asia, the Philippines' Alternative Learning System (ALS) and Thailand's National Education Act of Basic Education 2542 (1999), for instance, strive to make Non-formal Education more inclusive and integrated into lifelong 
learning (Ouane, 2009). The Republic of Korea has also implemented a lifelong Education Strategy in order to build a learning society where all citizens may find adequate learning opportunities in any place and at any time. (Ouane, 2009). According to (UNESCO, 2008), China has been continuously increasing its financial expenditure on Education and adopting a series of Educational laws that have guaranteed a healthy development of the ACE Programmes.

Despite these many gains especially after CONFINTEA V and V1 conferences, there are still low overall rates of participation, inappropriately trained and underpaid adult educators and inequity of ACE provision in terms of gender, geographical location, age and socio-economic status, in most countries. According to (UNESCO, 2003), there is a noticeable tendency to under-invest in ACE programmes in many counties In India for instance, the launch of National Adult Education program in 1978 ran aground due to demotivated learners and lack of interest in the programme by teachers. Singh, (1999) therefore observes that only when Adult learning is seen, assessed and evaluated as an Economic and Social investment will appropriate financing policies be possible.

\section{Challenges of ACE in Africa}

The successful completion of the CONFINTEAV1 conference did result in policy reviews in most African countries as well. Majority have adopted elaborate ACE policies as part of their National development strategies even though the sector rarely receives more than $5 \%$ of the National Education budgets. The African Union (AU) has proposed a well balanced comprehensive strategy which pays proper attention to issues of ACE programmes. Benin for instance launched a National Policy on Adult Education that contained the new vision, mission, objectives, strategies and resources needed to reach the defined goal. (Ouane, 2009). Burkina Faso too has a policy that includes a poverty reduction strategy paper revised in 2003. In its ten-year plan on education, one of the objectives is to promote literacy and Non-formal education (Ouane, 2009).

The resurgence of ACE programmes in the development programs of most African countries in the past 15 years has however been weak. Some do not still have clear policies on ACE Programs such as the Democratic Republic of Congo (DRC). In Cameroon for instance, there is no clearly defined law on Adult Education but has related laws passed from 2004 to 2007 to cover literacy and professional training. In Nigeria, (Moja, 2000) singles out the problem of poor implementation of policy as having contributed to the failure of Education in assisting in the social and economic development of the country.

Nnazov (2005) observes a shortage of qualified ACE teachers in most countries and asserts that it is common in developing countries for Adult Education Courses to be taught by teachers without Adult Education Training. Hinzen, (2007) also laments that most countries have legislation for Primary and Secondary schools as well as higher Education and usually, there is financial provision though often not high enough. The same however cannot be said of ACE as most countries have neither policies nor legislation for the programme and even more so often, only meagre finances are available for the sector.

\section{Challenges of ACE in Kenya}

The popularity of ACE programmes in Kenya started eroding way back in the mid 1980s especially when the Government started putting emphasis on Formal basic Education at the expense of the ACE programmes. Education for children, especially the poor ones was perceived by the Government as more important than the Education of their parents thus necessitating a competition over resources between the two sectors that started a downward trend in the provision of the ACE programmes. The fact that formal schooling is an unquestionable priority in the Education sector does not justify ACE programmes being left out.

According to (Seya, 2005), to make children to compete with their parents in the Education process is dangerous as it may create a break between two entities that are mutually dependent. In any case, it is the adults that experience poverty which research has positively linked with illiteracy, hence failure to enhance the education of the adults, only compounds the vicious cycle of illiteracy as they may unlikely be able to support their children's education. The Government, (Mulama, 2011) observes, lays too much emphasis on the Universal Primary Education (UPE), Free Primary Education (FPE) as well as the Girl-child Education while marginalizing the illiterate adult that is also in urgent need of Educational assistance. The country therefore continues to witness rising levels of Adult illiteracy.

The 1999 population census for instance, estimated that there were 4.2 million illiterate adults in the country, 60\% of whom were women. The Human Development Report published in 2004 by the United Nations Development Program (UNDP), similarly pointed out that close to $16 \%$ of Kenya's adults are illiterate with $80 \%$ of them being women. A recent survey- the Kenya National Adult literacy Survey (KNALS) - conducted between June and August 2006 by the Kenya 
National Bureau of Statistics (KNBS), also reported very high Adult illiteracy approximated at 7.8 million young people and adults. This does not augur well for a country that wishes to industrialize by the year 2030 especially that research findings have shown that the mothers' literacy levels influence the education of their children.

Not Only has enrolment in Adult literacy programs in Kenya been declining steadily, but the programmes have lost their original vibe and become so low keyed that even the providers of the programmes have either pulled out or withheld their services. The acute shortage of ACE teachers for instance is an issue of concern as it undermines the effective promotion of literacy and adult education in the country. Most research also points to low budgetary allocation devoted to ACE programmes, suggesting the low priority given to ACE programmes. Owing to the participation of a variety of providers in the programmes, there is need for proper monitoring and co-ordination to ensure quality but from National Report of Kenya on Adult education of 2008, this is lacking. The report notes the difficulty to even determine the actual level of resources invested in the programmes in any one year.

\section{Challenges facing ACE sustainability in Nakuru North District}

\subsection{Availability of teaching personnel and sustainability of the ACE programmes}

Full time teachers, studies have shown, stabilize any education program and contribute heavily in the mobilization and participation of learners. However, findings from the (KNALS, 2007) reveal a 40\% decline in adult teacher recruitment as well as a high turnover of teachers thus hindering access to the ACE programmes. Those who left service either on early retirement, new opportunities, retrenchment or even death have not been replaced. Karan, (1996) for instance attributes the declining enrolment in Adult Education to the inability to recruit adequate and qualified teachers. Majority of the teachers currently serving are either self help or part-ime who are paid a token for volunteering to teach adults. They are poorly remunerated, lack essential skills and mostly come from the rank of retired teachers or O-level Form four school leavers. (Kebathi, 2008).

Even the foreign funded Education services, (Singh, 1999) observes, are sometimes also delivered by unpaid volunteers such as students and activists who may or may not have the professional training required for the job. A UNESCO Report on Adult Education of 2005 sums up these in its observation that Adult Educators are inappropriately trained, hold minimal qualifications, are underpaid and work in educationally unfavourable conditions. This has prompted outbursts from many education activists, for instance, (Mulama, 2011) asserts that it is a mockery of justice to have only a handful of teachers to cater for the millions of adults, as with no teachers, learners may not see the reason for attending classes.

There is also a lack of professional development that can enhance Adult teachers' efficiency and help them gain new knowledge and adopt new practices in the ACE Programmes. According to (Bradley and Holman, 1996) there is need for Adult Education teachers to adapt to the present needs and influence of the Adult learners. This is so because it's likely that the Educators may find that they are younger and less "world wise" than some of their students or as (Timarong et al, 2003) observes, some of the adult learners may have been out of school for a long time or may never have attended school in the first place, they will therefore need help from the Educators to acquire study skills and techniques to recall information learnt and to apply it to their day to day experiences. Their thinking process may also be slow with age hence need more time to grasp new concepts or demonstrate the knowledge learnt.

\subsection{Availability of teaching-learning facilities and the sustainability of the ACE programmes}

Teaching and Learning materials have long been established as great facilitators of learning at all levels of education, ACE programmes included. According to (Moulali, 2005), the quality of Education process at all levels is enhanced by the availability of teaching and learning materials such as textbooks, teachers' guides as well as physical facilities. Moja, (2005) also points out that poor conditions of buildings due to lack of maintenance and repair may cause brain drain of teaching and administrative personnel out of the Education Sector or even worse, contribute to high Adult learner dropouts from school.

Most Previous studies indicate a lack of seriousness in ACE provision especially in equipping the centers with the necessary materials to enhance a conducive learning environment. Kebathi (2008) points out that Adult learning centers lack adequate and relevant teaching and learning materials and that most of the learning venues are community owned places such as public schools, churches, mosques and halls. The furniture in these centers is also inappropriate. This may de-motivate the learners and result in absenteeism or even drop-outs.

The Lack of, or inadequacy of physical and instructional facilities in government owned Adult Education training 
centers, (Nnazov, 2005) observes, is indicative of neglect or the marginal status of Adult Education. This mainly is due to the low amounts of budgetary resources devoted to ACE programmes that are insufficient to cater for all the needs. The UNESCO report on the quality of education of 2006 pointed out that there is a noticeable tendency to under-invest in ACE programmes across many nations of the world. (Rue de la Concorde 60, 2006) for instance asserts that if public subsidies to individual learners are restricted to formal Education or vocational training, then, there is a danger that general Adult Education will be considerably weakened.

\subsection{Adult learner economic background and sustainability of ACE programmes}

Adult learners, as already mentioned elsewhere in the study come from various backgrounds that affect their participation in the ACE programmes. Karan, (1996) for instance blames a decline in Adult literacy enrolment in Kenya on Socioeconomic factors which discourage some adults from attending classes. One of these major factors includes high poverty levels. According to Mulama, (2011), high levels of poverty in the country have had an adverse effect on the Adult Education Programmes as learners give priority to looking for food and other basic requirements hence, basic requirement of the learners, far much outweigh their intellectual needs. Government statistics in Kenya for instance indicate that $54 \%$ of Kenyans live below the poverty line of a dollar per day. In Nakuru County alone, the poverty levels, according to the Kenya 2009 population and Housing Census are $41 \%$ in the urban areas and $45 \%$ in the rural areas for people.

High poverty levels usually create very unique challenges to the success of any education program. They affect the attendance rate of the learners, the quality of instruction given as well as basic resource availability. According to (UNESCO, 2008), countries with the poorer literacy rates also have higher poverty levels and the worse the social situation; the less likely people are able to take part in Adult Education (Rue de la Concorde 60, 2006). A recent report by UNESCO, 2006 on Adult illiteracy, Brain Architecture and empowerment of the poor for instance revealed that high poverty levels have adverse effects on the health of the poor and this may compound schooling. Drinking contaminated water, lodine deficiency and depression commonly associated with the poor was shown to result into reduced intelligence and impaired visual motor functions that may result to drop-outs or lack of participation in ACE programmes by many adults.

Families from low socio-economic status' communities, Graham and Walsh, (1996) observe, are less likely to have the financial resources or time availability to support academic status. Considering that most centers are far from reach for most of the adult learners, they may lack money for transport, food and other basic needs which negatively impacts their participation. This is especially worrying taking in to mind that majority of the learners enrolled in the adult literacy classes in Kenya for instance, are from the poorer sections of the society (MOEST, 2005). This therefore means that most encounter competing priorities for survival hence have very little time and money for educational activities.

This situation, according to (UNESCO, 2005) is compounded by the increasing number of female headed households which is more prevalent in Kenya at 31\% compared with Tanzania at 23\% and Uganda at 21\%. Most of these women are illiterate themselves. According to the Institute of Economic Affairs, (2007), the cost sharing policy is also too demanding for the learners especially in the current hard economic times hence would most certainly push the adults out of the ACE classes. This is because the cost of living may be too high considering costs like transport, child care and course fees among others.

Poverty reduction is therefore a vitally important component of the ACE policy that must stand alongside political commitment, economic and community development as it is the integrated multi-agency approach that will build sustainable futures (Bagheri, 2009). Improving overall educational provision accessible to the poor therefore involves reprioritizing expenditure patterns in the sector with increased allocation, not just to basic education but also to informal Adult Education and literacy programmes (Oxaal, 1997).

\subsection{Adult learner socio-cultural background and the sustainability of ACE programmes}

The Kenyan population comprises many ethnic groups which imply many different socio-cultural differences that may impact on the provision of ACE programmes negatively. High quality education, according to (UNESCO, 2006), implies an environment that actively seeks out learners and assists them to learn using a wide range of modalities and one that recognizes that learning is linked to experience, language and cultural practices, gifts, traits and interests. It is for this reasons that (Graham and Walsh, 1996) urged that Adult Education teachers need to understand the students and their motives for attending the classes. This is because adults return to school while at the same time maintaining responsibilities such as businesses and family. They also have prior experiences with previous schooling hence 
understanding the diversity of their motivation can be the first step towards designing an effective methodology of teaching them.

One of these socio-cultural considerations includes family responsibilities such as collecting firewood, fetching water and care for the children which mainly affect women. Adult learners have multiple non-school related commitments and responsibilities that they must also attend to while pursuing their educational goals and this can be quite frustrating leading to drop outs from the adult literacy classes. These commitments, according to (Timarong et al, 2003) may also affect their retention capacity in school. Women for instance, will most likely be excluded from taking part in adult learning because of the double stress they encounter as workers and care takers for their families and children, hence lack sufficient time to attend school (Hinzen, 2007).

This is a very likely scenario in Kenya, given that women in most cultural societies bear the burden of fending for their families including even the construction of shelters. The requirement therefore for women to attend classes regularly, may hamper those women with heavy workloads who lack time and energy (Oxaal, 1997). However, although many have disrupted lives and may be unable to commit themselves to regular and sustained learning programmes, adult learners at any age, can learn and succeed in their pursuits if they are afforded the opportunity, assistance and support that they need especially from the adult educators.

Another aspect is adult learner attitudes to ACE programmes. According to (Oxaal, 1997) the perception by learners of ACE programmes as inferior to formal schooling may lead to reduced access to further education and jobs despite the suitable qualifications. The programmes are associated with failures that could not access formal education hence many current and potential adult learners have a very low opinion of the programmes. A recent illiteracy survey in Teso County of Kenya, for instance, revealed an alarming $67 \%$ of the illiteracy rate and the main contributors to the escalating rates were reported as male. This is because, out of 1,148 learners registered for adult literacy classes, only 400 were men yet the illiteracy rate remained too high. (Olimere, 2011).

Some illiterate adults, according to (MOEST, 2005) also feel shy and are too stigmatized and embarrassed even to reveal their true literacy standards. Bradley and Goldman (1996) observe that in returning to school, adults feel they are relinquishing aspects of their adulthood roles and regressing to a former, and in many ways inferior status. There is therefore a sense in which they are going backwards in order to move forward. Some had left school under very unpleasant circumstances hence bring with them such emotional baggage such as fears, insecurities, self doubts and so forth.

Other socio-cultural factors having a bearing on ACE programmes include the language adopted as a medium of instruction. According to (UNESCO, 2006), learning opportunities are best when offered in the language which the learners feel most comfortable to express themselves and convey information and ideas. This poses a heavy challenge especially in a multi-lingual society as the case of Kenya may be. Culture therefore as (Behjat, 2007) observes, permeates learning hence in designing instructional environments, serious consideration must be given to the social and cultural dimension of the design and structuring of instructional materials and communication channels in order to cater for the culturally diverse learners.

\subsection{Policy implementation by the Government and sustainability of ACE programmes}

A coherent ACE policy (Nnazov, 2005), observes enables co-ordination of programs and activities and sets the scope and guidelines. It acts as a reference point for the partners as well as providing a framework for co-ordination and setting standards for quality and service thus enabling countries to meet such challenges in ACE like sustaining participation rates and stimulating and motivating prospective learners. This is why national development or competitiveness, no matter how passionately desired, is not likely to occur to any meaningful extent if a county is not earnestly committed to a sustainable and coherent ACE policy, purposefully articulated within its development goals.

Adult Education according (Ouane, 2009) is an inalienable human right thus suggests that it be enshrined constitutionally by all countries to ensure its effectiveness and practicability. Initiatives to restructure Education therefore will only be meaningful if they are endorsed and articulated at political levels.(Ekundayo, 2007) This will commit the governments to take Adult Education as serious as other Pillars in development. According to (Rue de la Concorde 60, 2006), an effectual policy should be backed up by legislation so as to ensure its full implementation and enable the concrete actions taken to bear fruit. Keriga, (2009) for instance, advocates that policies take place within a political framework of real participatory democracy and good governance of both National and local levels.

Other researchers however argue that enshrining Principles and regulations in law do not necessarily achieve the intended results, rather, sustained political will and effective partnership is needed to convert the intentions into practice. Kenya like many other countries of the world for instance has adopted a devolved government that enhances 
management of essential services including education, by the local people. World Bank, (2008) points out that decentralization of the Education system, requires strong political commitment and leadership in order to succeed as decentralization can substantially improve efficiency, transparency and accountability and responsiveness of service provision compared with the strong centralized system.

The Government also needs to promote Literacy surveys and Curriculum development. For instance, (Ouane, 2009) observes that Adult learning and Education Programs are rarely responsive to indigenous people, rural populations and migrants. The diversity of learners in terms of age, gender, cultural background, Economic status and unique needs such as disabilities and language are not reflected in the programmes. Hinzen, (2007) therefore questions how possible it is to improve employability of the work force without providing good quality education in general and vocational training for the youth and adults continuously.

\section{Conclusions}

From the above discussion, his paper concludes that Adult and Continuing Education is a key component of educational practice of any community. However it faces many challenges that have hampered its progress and once the challenges are addressed, adults will yied the goals of Education For All.

\section{References}

Adama Ouane, (2009). DVV International No. 75 DVV- Adult Education for a Viable Future.

Bagheri Masoumeh, (2009). European Journal of Social Sciences- Volume number 2. Impact of Socio-economic and Educational Status on the Family's health.

Bosire Conrad Mugoya, (2010), Devolution and Conflict Resolution. Assessing the Potential Role and Capacity of County Governments in Enhancing Local Peace in Kenya.

Bouaissa Mohsen, (2009), Human Capital Theory. Returns to Education and the Joy of learning-Evidence from Canadian data. Labour Market Research and Forecasting Human Resource and Skills Development in Canada. Preliminary and Incomplete Version.

Bradley L. and Juliette D., (1999). Educational Providers' Views of Students Who Return to School. Griffith University, Gold coast, Queensland, Australia

Briggs L. (2009). Australian Government-Australian Public Service Commission. Contemporary Government Challenges; Policy Implementation Through a Devolved Government- Helps delivery to better meet government and citizens' needs.

Chinese Adult Education Association, July 30th, (2008), National Report, Adult Education andLearning in China. Development and present situation. Chinese National Commission for UNESCO and Chinese Adult Education Association.

Carron, G, (1990). The Functioning and Effects of the Kenya Literacy programmes. African studies Review.

Cullen J, (1978). The Structure of Professionalism-A Qualitative Examination. New York, Petrocelle

Diamond I. (2008). Challenges and Change in Further Education. A Commentary By The Teaching and Learning Research Programme.

DVV Publication, Adult Education and Development Education No. 71, International Reflection on Issues Arising From The Benchmark and Call for Action Meaning Literacy. The Kenya National Adult Literacy Survey.

Ekundayo T.D Thompson, (2007). DVV International- DVV Publication. Adult Education andDevelopment Edition No. 56. Literacy and Basic Education-Transforming the Adult Education Agenda Through the Kenya Post Literacy Project.

Fitzsimons P. , Human Capital Theory and Education, University of Auckland

Freire P.(1973). Education for Critical Consciousness. New York Seabury Press.

Glen D. Israel, (1992), Sampling the Evidence of the Extension Program Impact, University of Florida-IFAS Extension.

Government of Kenya (GOK), (2005). MDGs in Kenya-Needs and Costs. Report by Ministry of Planning and National Development, courtesy of the United Nations Development Program (UNDP) and the Government of England.

Graham C. and Mark M., (June 1996). Adult Education, ESL, Teachers Guide. Adult Education Centre, Texas A and I University, Kingsville, Texas.

Hinzen H., (2007). Commission on Adult Education Organization and Financing - ICAE 7THWorld Assembly, Nairobi, Kenya, January $17^{\text {th }}-19^{\text {th }} 2007$.

Institute of Economic Affairs (IEA), (2007). Engendering Education Sector Budget. Reforming Future Education Sector Budgets. Education Position Paper. The institute of Economic Affairs (IEA) Pre-Budget. MPET Education Sector - 2007

Kebathi Joyce, (2008). DVV International, Kenya Institute for Public Policy Research and Analysis (KIPPRA), Working Paper No. 4. 2001 Social Sector Division, May 2001

Kenya National Bureau of Statistics (KNBS), (2009). Kenya Population and Housing Census

Kenya National Bureau of Statistics (KNBS), (2007). Kenya National Adult Literacy Survey Report.

Keriga L. and Abdullah B, (2009). Social Policy, Development and Governance in Kenya. An Evaluation and Profile of Education in Kenya Development Policy Management Forum (DPMF)

Kimberlin L. and Almut G. (2008). American Journal of Health Systems. Pharmacy Vol 65, No. 232276-2284

Knowles M. (1984), Andragogy in Action. Applying Modern Principles of Adult Learning. San Francisco, Jossy Bass. 
Lace R., (2006), Adult Education in Practice-Teaching Methods and Course Structure-Adult Education Tip sheets.

Marshall Gordon, (1998). Human Capital Theory-A Dictionary of Sociology.

Mckimm J. \& Carole J. , (2003). Facilitating Learning, Teaching and Learning Methods.

Miller J., (2005). Western International University-RESC 200. Graduate Research Methods.

Ministere de L' Education, (2002). Government Policy on Adult Education and Continuing Education and Training, Learning Throughout Life.

Ministry of Education (MOE), (2010). National Adult and Continuing Education Policy.

Ministry of Education (M.O.E), (2008). Development of Education. National Report of Kenya.Report Presented at the International Conference on Education-Geneva 25 $5^{\text {th }}-28^{\text {th }}$ November, 2008.

Ministry Of Education, Science and Technology (MOEST), 2005.Republic of Kenya. KenyaEducation Sector Support Programme (KESSP), 2005-2010.

Ministry of Gender, Labour and Social Development, April, 2008. National Report on the Development and State of Art of Adult Learning and Education (ALE) in Uganda - Final Draft.

Moja T., (2000). Nigeria Education Sector Analysis; An Analytical Synthesis of Performance and Main Issues.

Moulali Shalk, (2005). Promoting Lifelong Learning in Today's Global Environment. Effects of Different Teaching and Learning Methods. St. Clements' University

Mualuko J., Muthama H., Ipara O. and Obaki S., (4th July, 2009). Adult Education, Learners' Recruitment; Challenges and Prospects for Re-engineered Access to Adult Education in Kenya.

Mulama J., (2011). Education - Kenya. Mastering The ABCs Is Not Always Child play. Inter press Service News Agency (IPS) Friday, Dec $23^{\text {rd }} 2011$ at $10.10 \mathrm{GMT}$.

Nnazov R., (2005). Adult Education in Nigeria. The Consequences of Neglect and Agenda for Action. International Education Journal, Sharon Research Press, USA.

Okemakinde T. and Olaniyan D., (2008). European Journal of Scientific Research Vol 24, 0. 2. Human Capital Theory; Implication for Educational Development

Oluoch P.A, (2007). DVV International; Low Participation in Adult Literacy Classes. Reasons Behind it. DVV. Publication- Adult Education and Development. Education No. 65- Literacy.

Otieno W. \& Christopher C., (2004), Research Consultation on Education outcomes and poverty (RECOUP). Kenyatta University Department of Educational Foundation.

Ouko J., (2011). Kenya -Nakuru County and Land crisis.

Oxaal Z., (1997). Bridge Development - Gender Education and Poverty; Swedish International Development Co-operation Agency (SIDA), Institute of Development Studies, University of Sussex.

Preece J., (2010). European Association for the Education of Adults. The Role of AdultEducation in Reducing Poverty. EAEA Policy paper; Adult Education and Poverty Reduction.

Rahman A. Ur, Statistical Analysis of the different Socio- Economic Factors Affecting the Education of North Western Pakistan. Journal of Applied Quantitative Methods,

Rue de la Concorde 60, (2006). Adult Education Trends and Issues in Europe.

Sebudubudu D., (2010) The Impact of Good Governance on Development and Poverty in Africa-Botswana. A relatively Successful African Initiative. University of Botswana Gaberone, Botswana.

Seya Pierre T. (2005), Adult Education and African Development in the context of Globalization.

Singh M., (1999). Fifth International Conference on Adult education (CONFINTEA V). The Economics of the Financing of Adult Learning, Institute of Education Hamburg, published by UNESCO Institute for Education.

Smith C. and Marilyn G., (2007). Research on Professional Development andTeacher Change- Implication for Adult Basic Education.

Timarong A., Marrianne T., and Wilma S., (2003). Pacific Resource for Adult Education and learning.

Trotman Collins and Rita Cop, 2009. Knowledge Economy of a learning Society- Whatever Happened to Radical Adult Education. Swansea University, Wales, United Kingdom.

UNESCO, (1994). Culture of Peace- Declaration of the 44th Session of International Conference on Education, Paris.

World Bank, (2003). Improving Adult Literacy Outcomes. Lessons from Cognitive Research for Developing countries. Documentation and Report, Publication No. 26286. 